John Carroll University

Carroll Collected

\title{
Ontogenetic colour change in Oreophryne ezra (Anura: Microhylidae) reflects an unusual shift from conspicuousness to crypsis but not in toxicity
}

M.W. Bulbert

Macquarie University, Australia

T. E. White

Macquarie University, Australia

Ralph Saporito

John Carroll University, rsaporito@jcu.edu

F. Kraus

University of Michigan-Ann Arbor

Follow this and additional works at: https://collected.jcu.edu/fac_bib_2018

Part of the Biology Commons, and the Ecology and Evolutionary Biology Commons

\section{Recommended Citation}

Bulbert, M. W.; White, T. E.; Saporito, Ralph; and Kraus, F., "Ontogenetic colour change in Oreophryne ezra (Anura: Microhylidae) reflects an unusual shift from conspicuousness to crypsis but not in toxicity" (2018). 2018 Faculty Bibliography. 21.

https://collected.jcu.edu/fac_bib_2018/21 


\title{
Ontogenetic colour change in Oreophryne ezra (Anura: Microhylidae) reflects an unusual shift from conspicuousness to crypsis but not in toxicity
}

\author{
MATTHEW W. BULBERT ${ }^{1}$, THOMAS E. WHITE ${ }^{1}$, RALPH A. SAPORITO ${ }^{2}$ and FRED KRAUS ${ }^{3}$ \\ ${ }^{1}$ Department of Biological Sciences, Macquarie University, North Ryde, NSW 2109, Australia \\ ${ }^{2}$ Department of Biology, John Carroll University, University Heights, OH 44118, USA \\ ${ }^{3}$ Department of Ecology and Evolutionary Biology, University of Michigan, Ann Arbor, MI 48109, USA
}

\begin{abstract}
Ontogenetic colour change (OCC) may signal a switch in defensive strategies across development. Commonly, juveniles use cryptic colours and transition to conspicuous coloration as adults. Extensive theoretical and empirical work suggest such a transition is more likely than the converse. Oreophryne ezra, a newly discovered frog from New Guinea, however, undergoes OCC that belies expectations. We investigated the notion juveniles are aposematic while the adults use crypsis. We quantified the extent of conspicuousness of O. ezra across life stages using spectrophotometry and models of avian vision; and analysed skin extracts for the presence of toxic alkaloids. As predicted, the juvenile colour patterns were estimated to be conspicuous to likely predators against the frogs natural viewing backgrounds, while adults consistently fell below the threshold of discriminability. However, we discovered no alkaloids in either juveniles or adults. This suggests the juveniles use alternative defensive chemicals, or the colour pattern has an alternative origin - to which we offer the hypothesis that juvenile frogs may be Batesian mimics of a synoptic species of weevil. This study highlights the potential for this system, and others like it, to inform our understanding of the adaptive significance of OCC and the selective drivers for different anti-predatory strategies.
\end{abstract}

ADDITIONAL KEYWORDS: adaptive coloration - mimicry - predation.

\section{INTRODUCTION}

Ontogenetic colour change (OCC) is a non-reversible change in body colour occurring as an animal transitions between different life stages (Booth, 1990; Grant, 2007; Wilson, Heinsohn \& Endler, 2007). It occurs across a diversity of taxa from arthropods to primates, yet in most cases we have little understanding of why OCC exists. It has been suggested though that studies on animals that express OCC will be key to answering why and how animals have acquired conspicuous coloration (Stevens \& Ruxton, 2012) - a question that has been vigorously debated for over a hundred years (Poulton, 1890; Cott, 1940; Mappes, Marples \& Endler, 2005).

The variety of colour patterns seen in animals tends to reflect different defensive strategies (Ruxton, Sherratt \& Speed, 2004). For example, aposematic prey, when detected, deter predators by advertising unpalatability with conspicuous colours, while cryptic prey avoid detection altogether by matching the background colour patterns. Both strategies in their respective contexts are equally effective but just why one strategy is adopted over another is largely unknown. Theoretically, though aposematism is predicted to evolve when the opportunity costs associated with crypsis outweigh the costs of engaging in conspicuous behaviour (Ruxton et al., 2004; Higginson \& Ruxton, 2010). One such cost is constrained mobility, which may be imposed by the reduced effectiveness of cryptic coloration when in motion (Ioannou \& Krause, 2009). This restriction in movement limits potential foraging range and/or mating opportunities, both of which are increasingly important as an animal develops from juvenile to adult (Merilaita \& Tullberg, 2005).

Comparative analyses of taxa that use both aposematic and cryptic strategies overwhelmingly support the notion aposematism is more likely to occur in larger 
species and at later developmental stages. In dart-poison frogs, for instance, larger species are more likely to be conspicuously coloured (Hagman \& Forsman, 2003; Rudh, 2013). While in the polymorphic strawberry poison frogs the populations with conspicuous coloration have a greater mean body size than their cryptic counterparts (Rudh, 2013). Likewise, animals in general that switch between crypsis and aposematism adopt conspicuous colours later in their development, when they are much larger in size (Grant, 2007; Higginson \& Ruxton, 2010; Valkonen et al., 2014). A transition in the contrary direction, from aposematism to crypsis, is also theorized under certain circumstances, for instance, if advertising at a larger size increases the risk of predation by predators that are not toxin averse (Higginson \& Ruxton, 2010). In such instances, then switching to another tactic may be of greater benefit. However, exemplar natural systems with which to examine these theoretical claims have yet to be empirically confirmed.

Although body size is strongly correlated with aposematism, it is not the only trait that has been implicated in determining when aposematism is most appropriate. For instance, nocturnal animals are generally cryptic coloured to aid with hiding during the day, whereas animals that are diurnal may adopt a more conspicuous lifestyle (Merilaita \& Tullberg, 2005). In frogs, species that are conspicuously coloured are strictly diurnal (Myers, Paolillo \& Daly, 1991; Grant et al., 2006). Animals that shift their diel activity across life stages potentially provide an opportunity to disentangle the relative importance of light conditions and body size as constraints on adaptive coloration strategies. In frogs, such shifts are unknown apart from our study animal.

The Papuan frog, Oreophryne ezra - only recently described from an island south-east of New Guinea (Kraus \& Allison, 2009) - displays a dramatic agerelated change in coloration and behaviour unlike other frogs. The original description described the juveniles as glossy black with yellow spots, whereas adults are uniform pink/peach with an iridescent blue iris (Kraus \& Allison, 2009). Juveniles were also reported to sit conspicuously exposed on vegetation during the daytime and not easily disturbed, both of which are unique among Papuan frogs in the experience of F.K. (based on $>6500$ frogs of 220 species), whereas adults are only active at night and, like many other Oreophryne species, often call from hidden arboreal sites and are averse to human approach. On first appearances, the coloration in juvenile $O$. ezra has a striking general resemblance to patterns displayed by dart-poison frogs and, specifically, is similar dorsally to Oophaga arborea, Ranitomeya vanzolinii and some Oophaga histrionica. In addition, yellow contrasting with black is common among aposematic organisms (Summers et al., 2015) more generally and has been experimentally shown to ward off predator advances (Schuler \& Hesse, 1985). In contrast, the lack of contrasting coloration in the adults, and their nocturnal behaviour, suggests they are not aposematic and are instead either cryptic or their body colour is not important for avoiding detection.

We provide the first investigation of the potential adaptive basis of coloration for O. ezra, which undergoes extreme OCC. Specifically, we tested the hypothesis that OCC, in O. ezra, reflects a shift in defensive strategy across life-history stages; from aposematism in juveniles to crypsis in adults. This makes two general predictions, which form the basis of our study. First, the colour patterns of juveniles should be conspicuous to potential predators and, conversely, adults should be relatively inconspicuous in their natural viewing conditions (Mappes et al., 2005; Summers et al., 2015). Second, the putatively aposematic juveniles should possess chemical defences (Summers et al., 2015) while the adults dispel with such defence. Among conspicuously coloured diurnally active frogs, this often takes the form of alkaloids sequestered in the skin, which are a class of chemicals both distasteful and toxic to common anuran predators (Daly, 1995; Daly, Garraffo \& Spande, 1999; Daly, Spande \& Garraffo, 2005; Saporito et al., 2011). We tested each of these expectations.

\section{METHODS}

\section{HABITAT}

Oreophryne ezra are restricted to a cloud forest, $\sim 0.5$ $\mathrm{km}^{2}$, on the upper $170 \mathrm{~m}$ of Mt. Riu, Sudest Island $(-11.5063 \mathrm{~S}, 153.4311 \mathrm{E})$. Sudest Island is $866 \mathrm{~km}^{2}$ in extent and has a maximum elevation of $806 \mathrm{~m}$ a.s.l. lying $270 \mathrm{~km}$ ESE of the south-easternmost tip of New Guinea. The frogs were rather common during the survey period 5-18 August 2013. Forest was of short stature $(3-5 \mathrm{~m})$ with dense tangles of tree boles, shrubs and other vegetation.

\section{ANIMAL COLLECTIONS AND BEHAVIOURAL OBSERVATIONS}

Although juveniles had been collected on a previous trip, there were no notes on exactly where they were found or what the juveniles were doing when collected. We conducted an extensive search to locate them and to establish the range of backgrounds on which the animals perched if indeed they did. All juveniles were seen in a relatively open area just below the summit. Juveniles were then later collected opportunistically by hand, within this region, mostly during the morning from 0600 to $1200 \mathrm{~h}$. We collected adults at night when they were active. Males engaged in advertisement calling, primarily from Pandanus, either on or 
among the leaf litter or from the layered bark. On occasion, we observed them calling in the relative open on adjacent vegetation. Adults were never observed in the open during the day. Twenty-two focal juveniles were observed for $30 \mathrm{~min}$ each, to assess the activity budget and to describe the movement pattern to establish the range of backgrounds they may use.

\section{SPECTRAL REFLECTANCE}

We measured frog colour ( $n=19$ juveniles, 30 adults) and background material in situ using a portable spectrophotometer fitted with a cosine corrector (Jaz EL-200, Ocean Optics, Dunedin, FL). We took readings with the probe held perpendicular to the measurement surface, maintained at a working distance of $5 \mathrm{~mm}$ by a polycarbonate probe-tip. All settings were kept consistent at an integration time of $180 \mathrm{~ms}$, a boxcar width of three, and five spectra averaged per measurement. We recalibrated the spectrophotometer between measurements using a Spectralon 95\% white standard. Owing to the minimum-achievable sampling area of $c .5 \mathrm{~mm}$, readings of juvenile coloration came from either larger individuals that had yet to fully transform, or from larger spots found on the flank or thigh of smaller individuals. To quantify viewing backgrounds, we measured the reflectance of surfaces the juveniles were found on (e.g. fresh leaves and bark), and the accumulated leaf litter in the core of palm-like Pandanus, within which adults typically reside.

\section{VISUAL MODELLING}

To estimate the subjective conspicuousness of frogs across life stages, we used the log-linear receptornoise-limited model with a tetrachromatic avian visual phenotype (Vorobyev \& Osorio, 1998; Vorobyev et al., 1998), as birds are almost certainly the predominant predator (Brass, 1959). This allows for the estimation of chromatic (hue/saturation; $\Delta \mathrm{S}$ ) and achromatic (luminance, or subjective 'brightness'; $\Delta \mathrm{L}$ ) distances between stimuli in units of Euclidean, noise-weighted 'just-noticeable distances' (JNDs), assuming the limits of colour discrimination are set by photoreceptor and neural noise (see Supporting Information for full model details). We used the package 'pavo' (v 1.0; Maia et al., 2013) in $\mathrm{R}$ (v 3.2; R Core Team, 2014) for all spectral processing and visual modelling.

Following initial visual modelling, we used a twostep approach to estimate the chromatic and achromatic discriminability of colour patches against natural backgrounds, and pattern elements against one another (Maia \& White, 2017). We first used a permutational multivariate analysis of variance
(PERMANOVA; Anderson, 2001) on chromatic $(\Delta \mathrm{S})$ and achromatic $(\Delta \mathrm{L})$ distances to statistically test the separability of groups in colour space. We used a PERMANOVA instead of parametric alternatives as it appropriately accounts for the multivariate nature of colour space distances, and does not rely on the assumptions of multivariate normality and homogeneity that are typically violated by visual model data (Maia \& White, 2017). For our analysis of juvenile frogs, we included spots, dorsa and background material as distinct groups. When analysing adult frogs, we included dorsa and background material. If groups were identified as statistically distinct by PERMANOVA, we then used a bootstrap procedure to estimate whether patches were discriminable to avian viewers (i.e. perceptual 'effect sizes'). For a given run, we sampled points from each group - equal to the size of the original group - with replacement, and estimated the distance between the centre of each distribution. We repeated this process 1000 times, generating a distribution of subjective chromatic and achromatic distances between groups, from which we calculated a $95 \%$ confidence interval. We then inspected this interval to predict the discriminability of groups in colour space. If it contained, or was entirely less than, the threshold value of $1 \mathrm{JND}$, then the patches were predicted to be indiscriminable to an avian viewer under ideal (i.e. laboratory) conditions (Siddiqi, Cronin \& Loew, 2004). Conversely, intervals that lie above this threshold suggested that such colour patches should be increasingly conspicuous to avian viewers (Fleishman et al., 2016).

\section{CHEMICAL COLLECTION AND ANALYSES}

\section{Alkaloid analysis}

Whole-skin extracts from 20 juveniles and 20 adults were transferred to $100 \%$ methanol in $4 \mathrm{~mL}$ glass vials with Teflon-lined caps. We applied the procedure outlined in Saporito et al. (2010) for extracting alkaloids from the skins (see Supporting Information for full procedure).

\section{ETHICS STATEMENT}

All handling and processing of frogs followed approved protocols from PNG National Research Institute. We also followed the ABS (Animal Behavior Society)/ ASAB (Association for the Study of Animal Behaviour) 'Guidelines for the treatment of animals in behavioural research and teaching'. The PNG Department of Environment and Conservation, PNG National Research Institute, and Milne Bay Provincial Government approved the work and provided permission for all fieldwork activities. 


\section{RESULTS}

\section{BEHAVIOUR AND OBSERVATIONS}

All juveniles we observed were perching diurnally in the open (Fig. 1A) some of which were sitting in full sunlight. Of the juveniles collected/observed, 39\% were seen on trunks of palms, young saplings or small trees; $56.5 \%$ were perched on leaves of vines, Pandanus, or fronds of ferns and palms; and a single individual was on the ground. Apart from one individual observed scaling a tall palm $(\sim 3 \mathrm{~m})$, individuals on woody material were often found on pieces hollowed out by ants. The twenty-two focal juveniles did not move for most of the 30 -min observation period ( $n=22 ; 99.24 \pm 0.88 \%$ time/ individual). Only three individuals, however, did not move at all. Movements consisting of walking ( $n=19$; $0.70 \pm 0.85 \%$ time/individual). The walking was discontinuous, with individuals moving in repeated short spurts $(n=19 ; 1.73 \pm 0.97 \mathrm{~cm} /$ individual, $\max =6.5 \mathrm{~cm})$ punctuated by pauses (often in mid-stride; Fig. 1C). Paused animals would often hold that posture for minutes before progressing further. Changes in direction of movement first involved rotating the head ( $n=14$; $0.03 \pm 0.03 \%$ time/individual) towards the new direction and pausing before setting a course in that direction. Other movements we observed included jumping
( $n=9 ; 0.02 \pm 0.03 \%$ time/individual; $2.75 \pm 1.37 \mathrm{~cm} /$ individual), striking with tongue $(n=5 ; 0.009 \pm 0.02 \%$ time/individual) and body push-up ( $n=1 ; 0.001 \%$ time/ individual). In contrast, during the day adults were not active and were only found by actively searching in the leaf litter that accumulates in the central leaf axils of Pandanus (Fig. 1D).

\section{COLOUR}

Smaller juveniles were primarily glossy black with strongly contrasting yellow spots (Fig. 1E), although to the naked eye the spots in the groin or adjacent region were more green, but these are typically hidden when at rest. Larger juveniles (Fig. 1F; SVL: 13-15 mm, $n=5$ ) and 'subadults' (Fig. 1G) were found in various stages of colour transition (Fig. 1E/Fig. 1F, G; see also Kraus \& Allison, 2009: fig. 1). Melanin appeared to disappear from the snout first, and the spots on the abdomen appeared to persist the longest. In contrast, the dorsal colour of adults was typically uniform in colour (i.e. without markings), but the prevailing colour varied between individuals (Fig. 1F-H). From a qualitative, human perspective, adults ranged from apricot to bright $\mathrm{red} /$ red-orange to variations of brown.

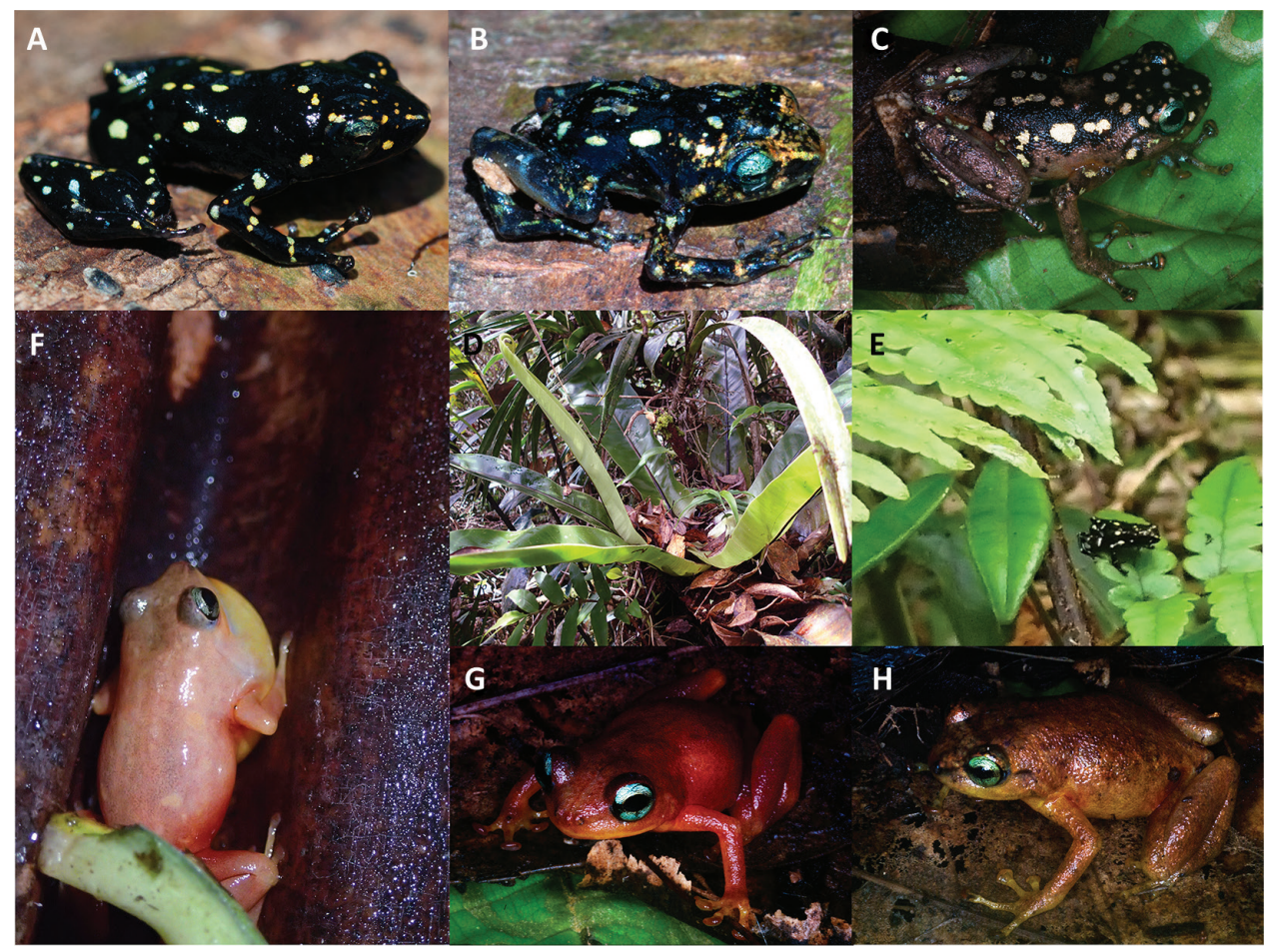

Figure 1. Juveniles 'basking' in the open (A) and on ant-hollowed wood (B); juvenile paused in mid-stride held for $\sim 3$ min (C); (D) leaf litter filled Pandanus - adult hiding place during the day; (E, F) transition of coloration from juvenile to subadult; $(\mathrm{G}, \mathrm{H})$ adult colour variation and example of a typical calling location $(\mathrm{H})$. 


\section{VISUAL MODELLING}

We found a distinct shift in the subjective conspicuousness of frogs across life stages: juveniles were predicted to be relatively conspicuous to potential visual predators, whereas adults were chromatically and achromatically cryptic in their environments. Specifically, we found that the colour-pattern elements and backgrounds of juvenile frogs were chromatically (PERMANOVA, $F_{2,140}=4.94, P<0.01$ ) and achromatically (PERMANOVA, $F_{2,140}=90.69, P<0.01$ ) separable in avian colour space (Fig. 2A, B). Our subsequent bootstrap-based analysis predicted that the contrast of juvenile spots against background material, as well as within-pattern contrasts (spots vs. surrounding dorsal base colour), is chromatically conspicuous (Fig. 2A, B; Table 1). The chromatic contrast of dark dorsal ground colour with the background material falls below the perceptual threshold of avian viewers. Achromatically, juvenile dorsa were predicted to generate strong contrast against background materials and exhibited high within-pattern contrast (Table 1), but the spots themselves were for the most part as bright as the background.
We found the dorsal coloration of adult frogs to be chromatically distinct from background material in avian colour space (PERMANOVA, $F_{1,111}=8.36$, $P<0.01$ ), though this difference was subsequently estimated to fall below the perceptual threshold of avian viewers (Fig. 2C, D; Table 1). Achromatically, adult dorsa and backgrounds were statistically inseparable (PERMANOVA, $F_{1,111}=0.17, P=0.68$ ).

\section{CHEMICAL ANALYSES}

GC-MS analysis of skin extracts revealed no detectable lipophilic alkaloids (Fig. 3).

\section{DISCUSSION}

We investigated the hypothesis that OCC in O. ezra reflects a shift in defensive strategies, more specifically, that juveniles use aposematism while adults rely on crypsis. Juveniles were perched during the day on high-contrast backgrounds, with some even found in full sunlight; behaviour consistent with being
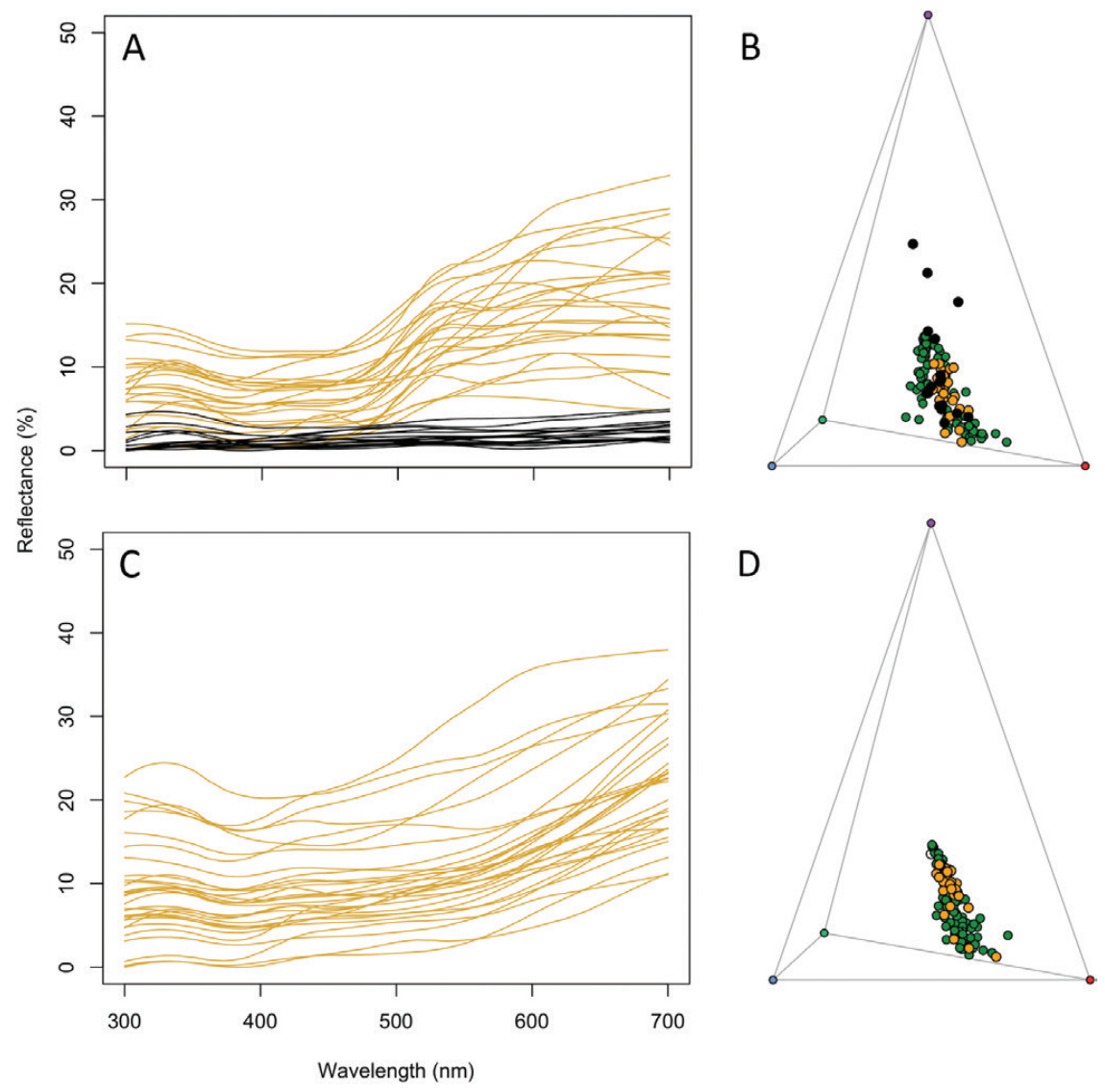

Figure 2. Reflectance spectra of (A) juvenile (black lines, dorsum; yellow lines, spots) and (C) adult (dorsum) body regions; $(\mathrm{B}, \mathrm{D})$ the spectra as modelled in a tetrahedral (average-UV avian) colour space, along with background foliage (green points). 
aposematic. They also moved erratically with long pauses between short-movement bouts of walking, similar to behaviours seen in aposematic frogs with spotted appearances (Rojas \& Devillechabrolle, 2014). As previously recorded (Kraus \& Allison, 2009), adults were not active during the day. Visual modelling supported the hypothesis that juvenile colour patterns are relatively conspicuous to potential avian predators and that adults are cryptic in their respective microhabitats (Table 1). However, the change in discriminability

Table 1. Estimated chromatic $(\Delta \mathrm{S})$ and achromatic $(\Delta \mathrm{L})$ contrasts (JNDs) of juvenile and adult body regions and backgrounds

\begin{tabular}{lcc}
\hline Comparison & $\Delta \mathrm{S}$ & $\Delta \mathrm{L}$ \\
\hline Juvenile & & \\
$\quad$ Dorsum/background & $0.56-1.82$ & $\mathbf{1 8 . 5 4 - 2 3 . 4 9}$ \\
Spot/background & $\mathbf{2 . 3 4 - 4 . 2 4}$ & $0.07-2.76$ \\
$\quad$ Dorsum/spot & $\mathbf{2 . 2 7 - 4 . 8 4}$ & $\mathbf{1 9 . 4 4 - 2 4 . 7 9}$ \\
Adult & & \\
$\quad$ Dorsum/background & $0.96-2.87$ & Not significant \\
\hline
\end{tabular}

Ranges represent $95 \%$ CIs for centroid distances between groups in a tetrahedral (average-UV avian) colour space, estimated using a bootstrap procedure. Groups whose intervals exceed the threshold value of 1 are predicted to be discriminable on average, and are indicated in bold. An estimate of achromatic adult-vs.-background contrast was not calculated since these groups were statistically indistinguishable (see main text). CI, confidence interval; JND, just-noticeable distance. was not mirrored by the chemical analyses, which failed to detect any alkaloids in either life stage.

Modelling predicted that bird predators should detect juvenile $O$. ezra more readily than adults. The yellow colour patches of the juveniles are predicted to be chromatically distinguishable from both the background substrate as well as the juveniles' own dark dorsal ground colour. The brightness of the markings contrasted strongly with the dark dorsa but not the perching substrate, suggesting the saliency of the yellow markings may rely more on the internal-pattern contrast rather than overall contrast with the background. Of interest is the apparent dominance of the dark coloration relative to the yellow markings. It has been shown, using model caterpillars exposed to wild birds, that models with higher proportions of black to yellow markings had greater survivability than if the model caterpillars were entirely yellow (Barnett, Scott-Samuel \& Cuthill, 2016). An animal uniformly brightly coloured can be perceived from a farther distance than one that has smaller patches, and it potentially runs the risk of attracting a predator not deterred by the coloration. In contrast, adult $O$. ezra were indistinguishable from their background and, unlike juveniles, varied somewhat in their predominant coloration. This variation in coloration broadly matches the mixed coloration of the leaf litter under which the frogs hide (Fig. 1D; Table 1), and the cryptic behaviour of adults during the day likely further inhibits detection by avian predators.

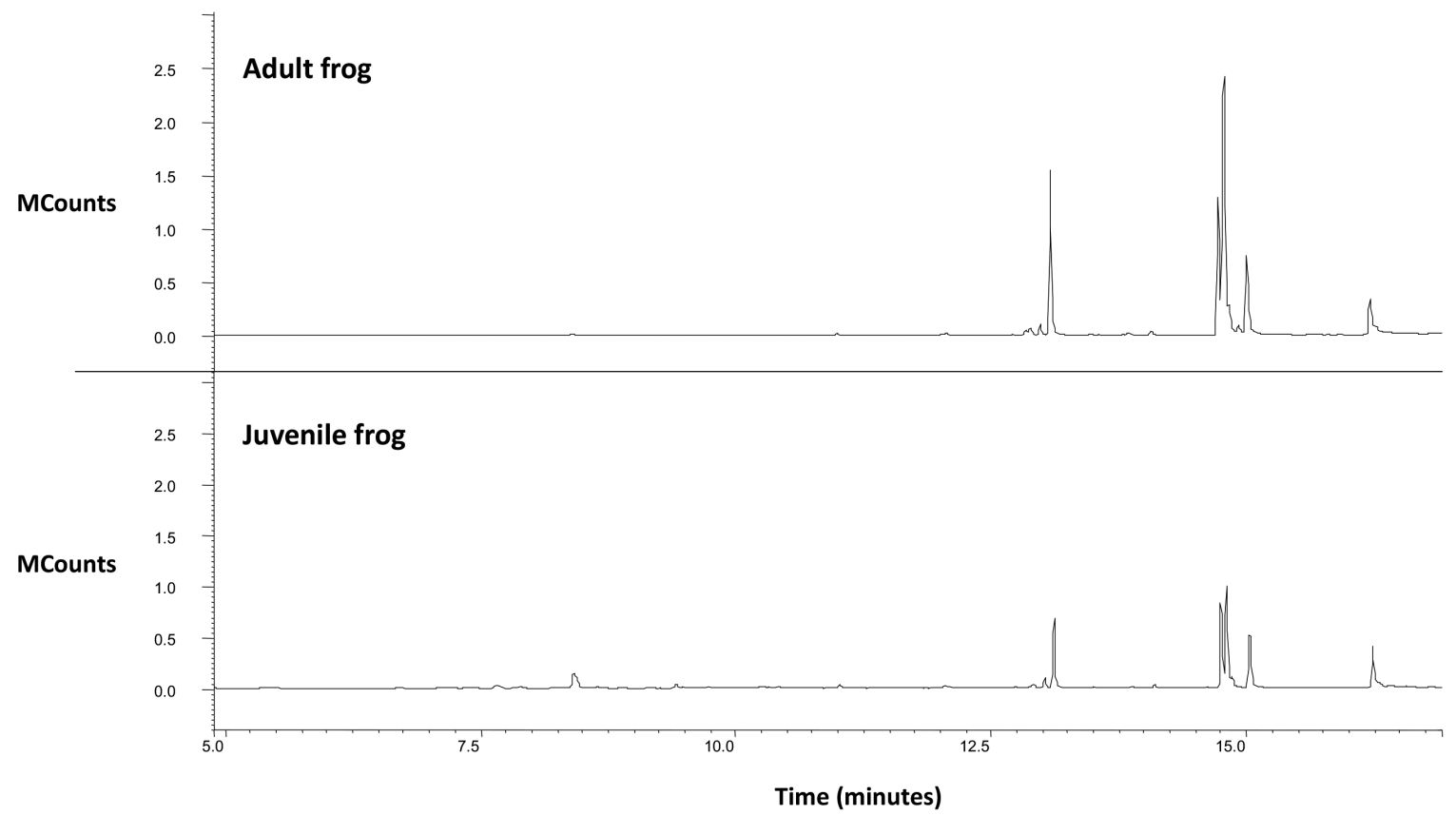

Figure 3. Gas chromatogram of skin extracts from an adult and a juvenile Oreophryne ezra. Chemical profiles were very similar among samples, and consisted largely of fatty acids. No alkaloids were detected. 
A hypothesis of aposematism predicts the subject animal to be defended (Summers et al., 2015), often chemically, but neither adult nor juvenile $O$. ezra tested positive for alkaloids in our study. Juvenile O. ezra appear to share traits with dart-poison frogs in that they are diurnal, perch in obvious locations, make no attempt to hide when approached, more haltingly, contrast with their background, and eat ants, which serve as a source of many dietary alkaloids (Daly et al., 2000; Clark et al., 2005). Given these parallels, we hypothesized that juvenile O. ezra may contain alkaloid-based chemical defences. Our finding of no alkaloids in their skins falsifies the second of these hypotheses; however, it does not falsify the hypothesis of toxicity more generally because it remains possible that they use some other toxic chemical instead. A diversity of peptides and steroid-based defences have also been implicated in anuran defence and, unlike alkaloids, are synthesized directly by the frogs themselves (Daly, 1995). In contrast, alkaloids are generally sequestered from the frogs' diet and potentially may take time to accumulate so other biosynthesized chemicals maybe more readily adopted (Jeckel, Saporito \& Grant, 2015). Testing for other classes of chemicals is thus required before we can fully discount that $O$. ezra uses a chemical defence.

Should O. ezra not rely on chemical defence, then an alternative explanation for its conspicuous colour pattern is required. Bright coloration used in advertising is positively correlated with body size in frogs, such that adults are more likely to be brightly coloured than juveniles (Hagman \& Forsman, 2003). Juvenile $O$. ezra contradict this trend, suggesting some factor restricts the colour form to these smaller juveniles. A potential alternative explanation to being toxic themselves is that they may be Batesian mimics of a syntopic species that is toxic (Smith, 1981). Intriguingly, we encountered a species of yellow-on-black weevil in the genus Pantorhytes (Stibick, 1978). Like O. ezra, it was day active observed moving slowly across the same vegetation as $O$. ezra and unlike other weevils it did not death feign when touched but instead would reach out with its front legs. The likely species is $P$. stanleyanus (Gressitt, 1966). The colour of the spots varies between collection locations, but on Sudest the spots are described as pale greenish yellow/white which corresponds with our own observations (Fig. 4). Pantorhytes species tend to range from 8 to $13 \mathrm{~mm}$ in length (Gressitt, 1966), which overlaps the size range of juvenile $O$. ezra (SVL: $10.37 \pm 2.08$; $n=31$ ) but not the adults (SVL: $25.72 \pm 2.08$ ) measured in this study. Pantorhytes species have been suggested to be either chemically protected or distasteful because predation on adults has not been observed (Smith, 1981). Assuming the weevils on Mt. Riu do not attain

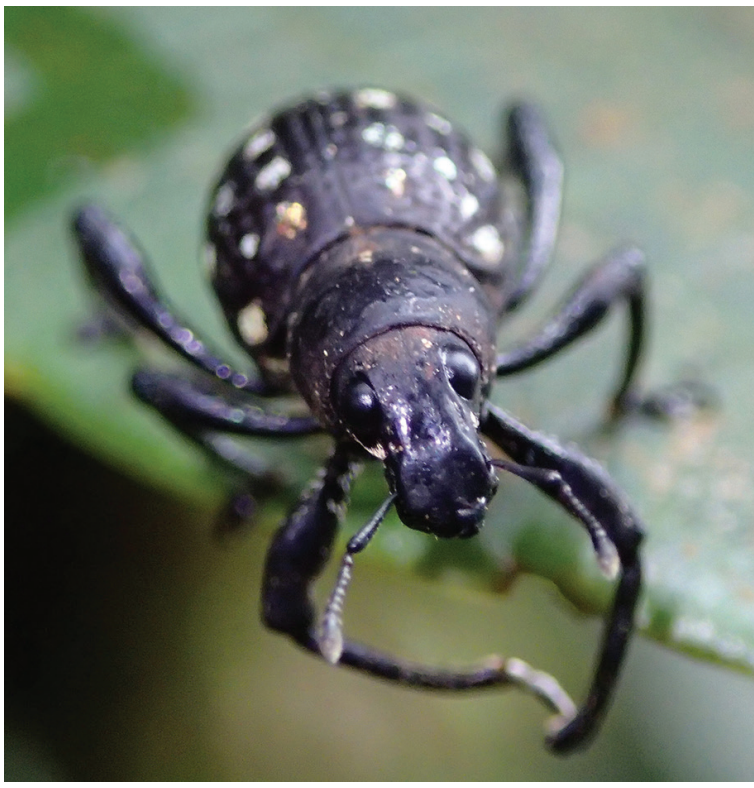

Figure 4. Pantorhytes sp. - likely P. stanleyanus - a potential model for Batesian mimicry by the juveniles of Oreophryne ezra.

a larger size, adoption of the colour pattern by the frogs when bigger would reduce the effectiveness of any mimicry by reducing their match to the model and by making them conspicuous at greater distances. The markings displayed by $O$. ezra resemble those of the lizard Heliobolus lugubris (Huey \& Pianka, 1977). Juveniles of this South African lizard are black with yellow spots and are said to mimic carabid beetles that use a chemical defence against predators. So, the suggestion of a vertebrate mimicking an invertebrate is not unprecedented.

In conclusion, we have shown that the colour pattern of juvenile O. ezra is likely conspicuous to potential visual predators, which differs from the cryptic coloration of adults. However, both life stages lack alkaloid defences in their skins. Two additional areas of research are immediately suggested for obtaining a better understanding of the evolutionary forces producing the remarkable ontogenetic shift in color pattern in this species. First, the presence of additional potential toxins beyond alkaloids needs to be investigated in this species. It may be that $O$. ezra uses peptides or other compounds are used for defence in this species, as is known for other frogs (Daly, 1995). Should such compounds prove absent, conclusively falsifying the hypothesis of aposematism, then the hypothesis that $O$. ezra juveniles mimic toxic models should be investigated. We have proposed Pantorhytes weevils as one possible syntopic model but there may be others that we did not observe during our observations. 


\section{ACKNOWLEDGEMENTS}

We thank the support crew of Charlie 'Cuptea' Graham, Neki, Ridges and Paul and the many helpers from Araeda village; the PNG National Museum and Art Gallery for providing in-country collaborative assistance; and the PNG Department of Environment and Conservation, PNG National Research Institute, and Milne Bay Provincial Government for permission to conduct this work. This research was supported by Australian Pacific Science Foundation grant to M.W.B. and National Science Foundation grant DEB 1145453 to F.K. Finally, we would like to thank Martin Whiting for invaluable advice throughout the project and the two anonymous reviewers and the editorial team for their helpful feedback on the manuscript.

\section{REFERENCES}

Anderson MJ. 2001. A new method for non-parametric multivariate analysis of variance. Austral Ecology 26: 32-46.

Barnett JB, Scott-Samuel NE, Cuthill IC. 2016. Aposematism: balancing salience and camouflage. Biology Letters 12: 20160335.

Booth CL. 1990. Evolutionary significance of ontogenetic colour change in animals. Biological Journal of the Linnean Society 40: 125-163.

Brass LJ. 1959. Summary of the fifth Archbold expedition to New Guinea, 1956-1957. Bulletin of the American Museum of Natural History 188: 1-69.

Clark V, Raxworthy C, Rakotomalala V, Sierwald P, Fisher B. 2005. Convergent evolution of chemical defense in poison frogs and arthropod prey between Madagascar and the Neotropics. Proceedings of the National Academy of Sciences 102: 11617-11622.

Cott BH. 1940. Adaptive coloration of animals. London: Methuen.

Daly JW. 1995. The chemistry of poisons in amphibian skin. Proceedings of the National Academy of Sciences 92: 9-13.

Daly JW, Garraffo HM, Jain P, Spande TF, Snelling RR, Jaramillo C, Rand AS. 2000. Arthropod-frog connection: decahydroquinoline and pyrrolizidine alkaloids common to microsympatric myrmicine ants and dendrobatid frogs. Journal of Chemical Ecology 26: 73-85.

Daly JW, Garraffo HM, Spande TF. 1999. Alkaloids from amphibian skins. In: Pelletier SW, ed. Alkaloids: chemical and biological perspectives. New York: Pergamon, 1-161.

Daly JW, Spande TF, Garraffo HM. 2005. Alkaloids from amphibian skin: a tabulation of over eight-hundred compounds. Journal of Natural Products 68: 1556-1575.

Fleishman LJ, Perez CW, Yeo AI, Cummings KJ, Dick S, Almonte E. 2016. Perceptual distance between colored stimuli in the lizard Anolis sagrei: comparing visual system models to empirical results. Behaviour, Ecology and Sociobiology 70: 541-555.
Grant JB. 2007. Ontogenetic colour change and the evolution of aposematism: a case study in panic moth caterpillars. The Journal of Animal Ecology 76: 439-447.

Grant T, Frost DR, Caldwell JP, Gagliardo R, Haddad CFB, Kok PJR, Means DB, Noonan BP, Schargel WE, Wheeler WC. 2006. Phylogenetic systematics of dart-poison frogs and their relatives (Amphibia: Athesphatanura: Dendrobatidae). Bulletin of the American Museum of Natural History 299: 6-262.

Gressitt JL. 1966. The weevil genus Pantorhytes (Coleoptera), involving cacao pests and epizoic symbiosis with crytogamic plants and microfauna. Pacific Insects 8: 915-965.

Hagman M, Forsman A. 2003. Correlated evolution of conspicuous coloration and body size in poison frogs (Dendrobatidae). Evolution 57: 2904-2910.

Higginson AD, Ruxton GD. 2010. Optimal defensive coloration strategies during the growth period of prey. Evolution 64: 53-67.

Huey RB, Pianka ER. 1977. Natural selection for juvenile lizards mimicking noxious beetles. Science 195: 201-203.

Ioannou CC, Krause J. 2009. Interactions between background matching and motion during visual detection can explain why cryptic animals keep still. Biology Letters 5: 191-193.

Jeckel AM, Saporito RA, Grant T. 2015. The relationship between poison frog chemical defenses and age, body size, and sex. Frontiers in Zoology 12: 27.

Kraus F, Allison A. 2009. A remarkable ontogenetic change in color pattern in a new species of Oreophryne (Anura: Microhylidae) from Papua New Guinea. Copeia 2009: 690-697.

Maia R, Eliason CM, Bitton PP, Doucet SM, Shawkey MD. 2013. pavo: an $R$ package for the analysis, visualisation and organisation of spectral data. Methods in Ecology and Evolution 4: 906-913.

Maia R, White TE. 2017. Comparing colours using visual models. bioRxiv $\mathbf{1 7 5 9 9 2}$.

Mappes J, Marples N, Endler JA. 2005. The complex business of survival by aposematism. Trends in Ecology \& Evolution 20: 598-603.

Merilaita S, Tullberg BS. 2005. Constrained camouflage facilitates the evolution of conspicuous warning coloration. Evolution 59: 38-45.

Myers CW, Paolillo OA, Daly JW. 1991. Discovery of a defensively malodorous and nocturnal frog in the family Dendrobatidae: phylogenetic significance of a new genus and species from the Venezuelan Andes. American Museum Novitates 3002: 1-33.

Poulton EB. 1890. The colours of animals: their meaning and use especially considered in the case of insects. London: Kegan Paul, Trench, Trubner and Co.

$\mathbf{R}$ Core Team. 2014. $R$ : a language and environment for statistical computing. Vienna, Austria: R Foundation for Statistical Computing.

Rojas B, Devillechabrolle J. 2014. Paradox lost: variable colour-pattern geometry is associated with differences in movement in aposematic frogs. Biology Letters 10: 20140193. 
Rudh A. 2013. Loss of conspicuous coloration has co-evolved with decreased body size in populations of poison dart frogs. Evolutionary Ecology 27: 755-767.

Ruxton GD, Sherratt TN, Speed MP. 2004. Avoiding attack. New York, NY: Oxford University Press.

Saporito RA, Donnelly MA, Madden AA, Garraffo HM, Spande TF. 2010. Sex-related differences in alkaloid chemical defenses of the dendrobatid frog Oophaga pumilio from Cayo Nancy, Bocas del Toro, Panama. Journal of Natural Products 73: 317-321.

Saporito RA, Donnelly MA, Spande TF, Garraffo HM. 2011. A review of chemical ecology in poison frogs. Chemoecology 22: 159-168.

Schuler W, Hesse E. 1985. On the function of warning coloration: a black and yellow pattern inhibits prey-attack by naive domestic chicks. Behavioral Ecology and Sociobiology 16: $249-255$.

Siddiqi A, Cronin TW, Loew ER. 2004. Interspecific and intraspecific views of color signals in the strawberry poison frog Dendrobates pumilio. The Journal of Experimental Biology 207: 2471-2485.

Smith E. 1981. Review of control measures for Pantorhytes (Coleoptera: Curculionidae) in cocoa. Protection Ecology 3: 279-297.
Stevens M, Ruxton GD. 2012. Linking the evolution and form of warning coloration in nature. Proceedings of the Royal Society B-Biological Sciences 279: 417-426.

Stibick J. 1978. The genus Pantorhytes (Coleoptera; Curculionidae) division $\mathrm{AI}$ additions and changes to the common and major cacao species [new taxa]. Pacific Insects 18: 115-136.

Summers K, Speed MP, Blount JD, Stuckert AM. 2015. Are aposematic signals honest? A review. Journal of Evolutionary Biology 28: 1583-1599.

Valkonen JK, Nokelainen O, Jokimãki M, Kuusinen E, Paloranta M, Peura M, Mappes J. 2014. From deception to frankness: benefits of ontogenetic shift in the anti-predator strategy of alder moth Acronicta alni larvae. Current Zoology 60: 114-122.

Vorobyev M, Osorio D. 1998. Receptor noise as a determinant of colour thresholds. Proceedings. Biological Sciences 265: 351-358.

Vorobyev M, Osorio D, Bennett AT, Marshall NJ, Cuthill IC. 1998. Tetrachromacy, oil droplets and bird plumage colours. Journal of Comparative Physiology. A, Sensory, Neural, and Behavioral Physiology 183: 621-633.

Wilson D, Heinsohn R, Endler JA. 2007. The adaptive significance of ontogenetic colour change in a tropical python. Biology Letters 3: 40-43. 